\title{
Adolescent idiopathic scoliosis without limb weakness: a differential diagnosis of core myopathy?
}

\author{
Rafael de Paiva Luciano*, Eduardo Barros Puertas, Delio Eulalio Martins, Flavio Faloppa, David Del Curto, \\ Luciano Miller Reis Rodrigues, Beny Schmidt, Acary Souza Bulle de Oliveira and Marcelo Wajchenberg
}

\begin{abstract}
Background: Core myopathies are a clinically and genetically heterogeneous group of congenital myopathies with the common defined histopathological feature of focally reduced oxidative activity on muscle biopsy. It has a low incidence, however, recent articles show broad clinical spectrum, suggesting that the real incidence should be considerably larger than previously described. Due to the important association between scoliosis and paravertebral muscle imbalance, numerous authors study, by biopsy of the spinal rotator muscles, potential changes that may elucidate the etiology of adolescent idiopathic scoliosis.
\end{abstract}

Case presentation: Two patients have been followed at Spine Group of Department of Orthopedics at Federal University of São Paulo, with an initial diagnosis of idiopathic scoliosis. Both patients had clinical and radiological findings compatible with it. The patients authorized, through the Term of Consent, intraoperative biopsy of muscle multifidus from the apex of the thoracic curve on concave and convex sides. After muscle biopsy was performed a histopathological analysis. As regard to the histopathological features: in both patients were identified, the presence of core structures in extensive areas with reduced oxidative activity running along the muscle fiber.

Conclusions: All patients with 'idiopathic' scoliosis deserve a careful neurological evaluation, even if they have minimal muscle symptoms in the extremities. The frequent occurrence of scoliosis in patients with CORE Myopathies, supports the thesis that the change in the paravertebral muscle fiber must be the underlying pathogenic factor in scoliosis and may help us understand the onset and progression of curves in patients previously diagnosed with idiopathic scoliosis.

\section{Background}

Scoliosis is a common complication present in various neuromuscular diseases that develops as a result of progressive muscle weakness in the paraspinal musculature [1]. Neuromuscular scoliosis typically appears during advanced stages of disease, and this form is progressive and associated with deformities of the sagittal plane [2]. However, the most common form of this deviation is adolescent idiopathic scoliosis (AIS) which is a tridimensional deformity, defined as lateral deviation of the spine associated to vertebral rotation, with also sagittal plane implication. It occurs without a known cause in adolescents who

\footnotetext{
* Correspondence: rafaelluciano@ig.com.br

Universidade Federal de Sao Paulo - Brazil - R. Borges Lagoa, 783, 5 andar, Vila Clementino, SP Zip Code - 04038-031, Brazil
}

do not exhibit neurological or muscular disorders or other diseases [3-5].

Core myopathy constitutes a group of congenital myopathies that present histopathologic features of focal reduced oxidative activity in muscle biopsies and they are clinically and genetically heterogeneous [6-8]. Core myopathy was initially described by Magee and Shy in 1956 as having a low incidence, although recent studies have shown a broader clinical spectrum for this condition, which suggests that the real incidence is considerably higher than previously described [9-11].

We evaluated two patients with a diagnosis of AIS by collecting muscle multifidus biopsies during the surgical correction of their scoliosis deformities. During the histopathologic evaluation of these muscle fragments, 
we noted the presence of multiple core structures indicative of congenital core myopathies [6].

The clinical presentation of core myopathies can be widely variable, although most patients develop hypotonia or delayed motor development in early childhood. More severe presentations, such as fetal akinesia, as well as milder clinical scenarios of adult onset have also been described as manifestations of these myopathies. Furthermore, orthopedic complications such as scoliosis, congenital hip dysplasia, foot deformity, ligamentous laxity and patellar instability have also been associated with congenital myopathies [6]. The only clinical manifestation found in patients was the scoliosis. They demonstrated motor and neurological development adequate for their age. However, the presence of core myopathy symptoms without any associated weakness is not sufficient for a diagnosis of core myopathy [5].

The presence of progressive scoliosis in the two patients discussed here could be associated to the weakness of the paraspinal musculature. This weakness would be result of a mild form of myopathy or related to physiopathology of the AIS. The musculature analyzed was the multifidus, that arise from mammillary processes and pass to the spinous processes two to four level rostrad. Its main function is to act as agonist of the rotational movement of the spine [12]. Thus its

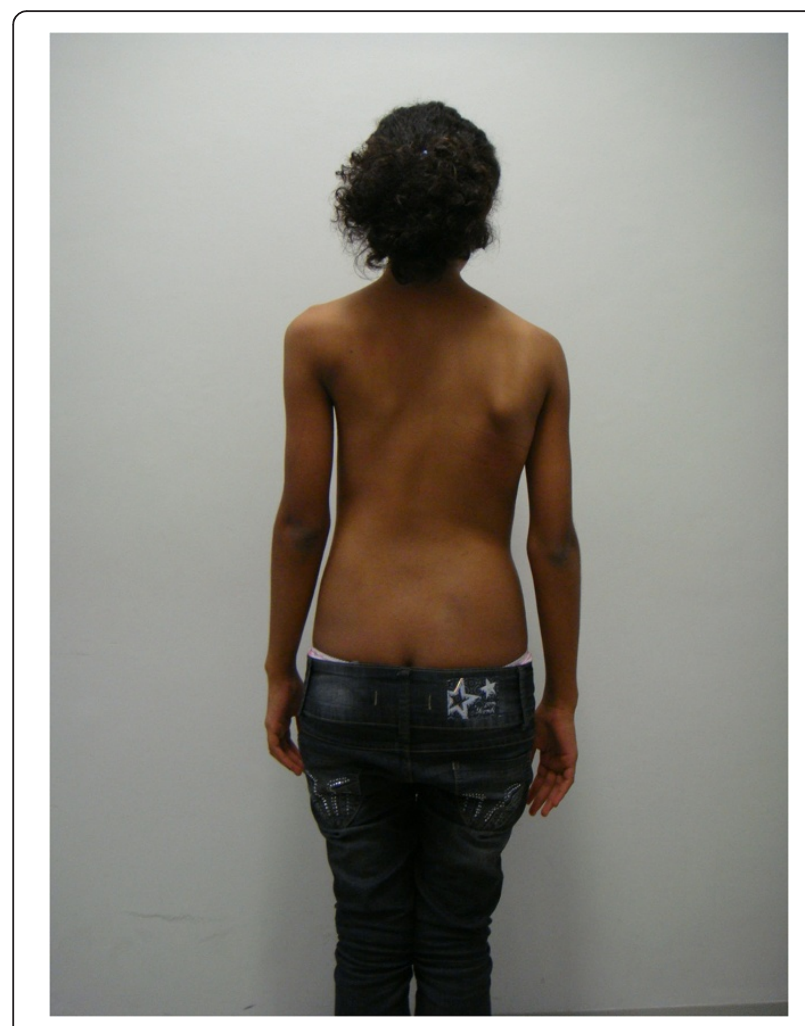

Fig. 1 Case 1: The patient's clinical aspect prior to surgery. Posterior view in orthostasis

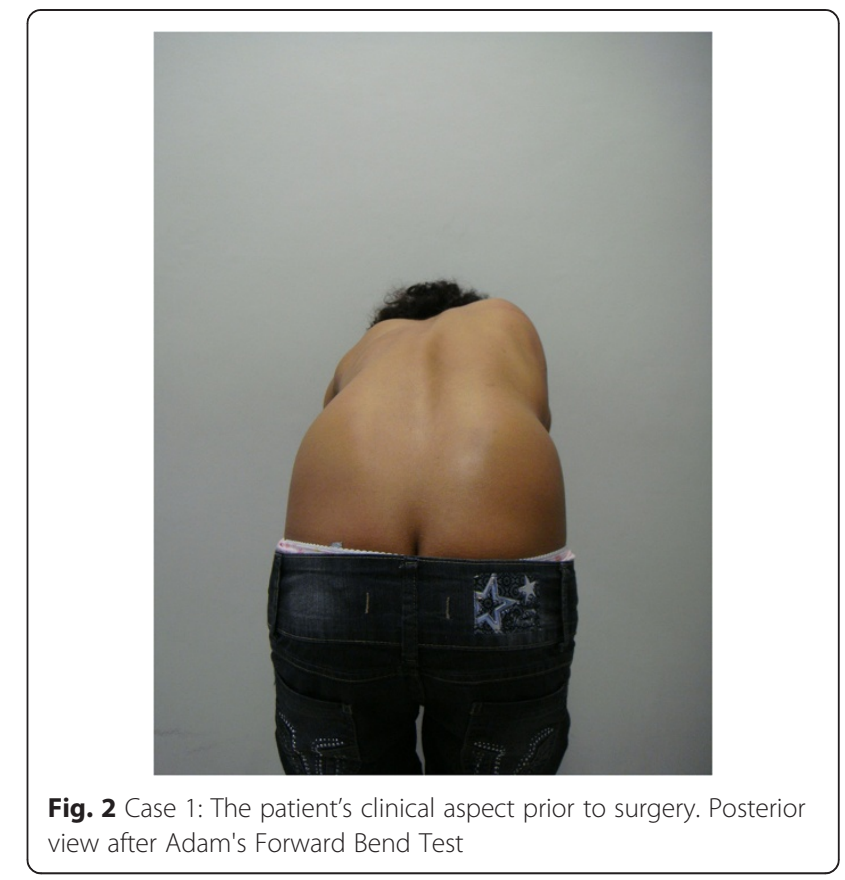

dysfunction could cause a rotational deformity, characteristic of AIS.

Of the known causative factors for the development of core myopathy, genetic factors seem to be most important, as mutations in the skeletal muscle RYR1 gene and less frequently in the SEPN1 gene contribute to disease development. The genetic analysis of the patients was not performed because initially the muscle disease was

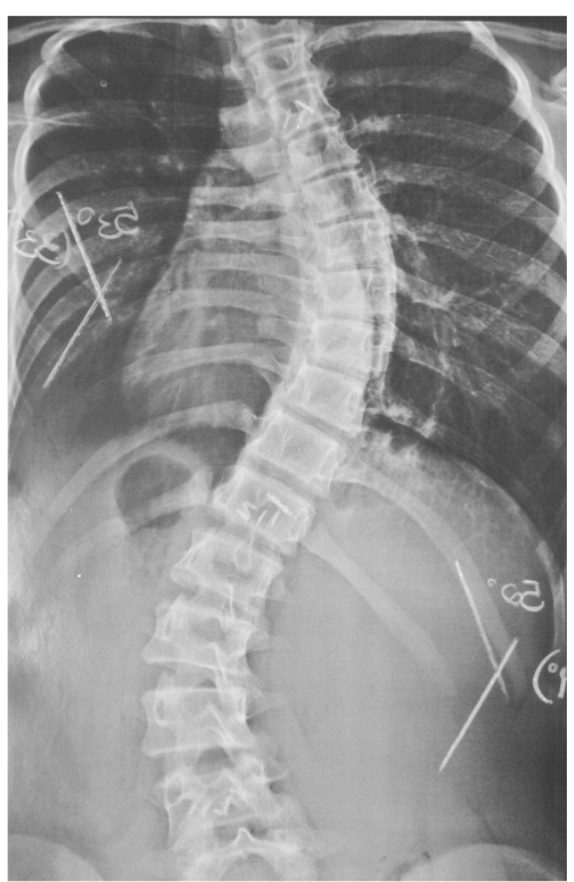

Fig. 3 Case 1: Radiological aspect of the scoliosis - AP view 


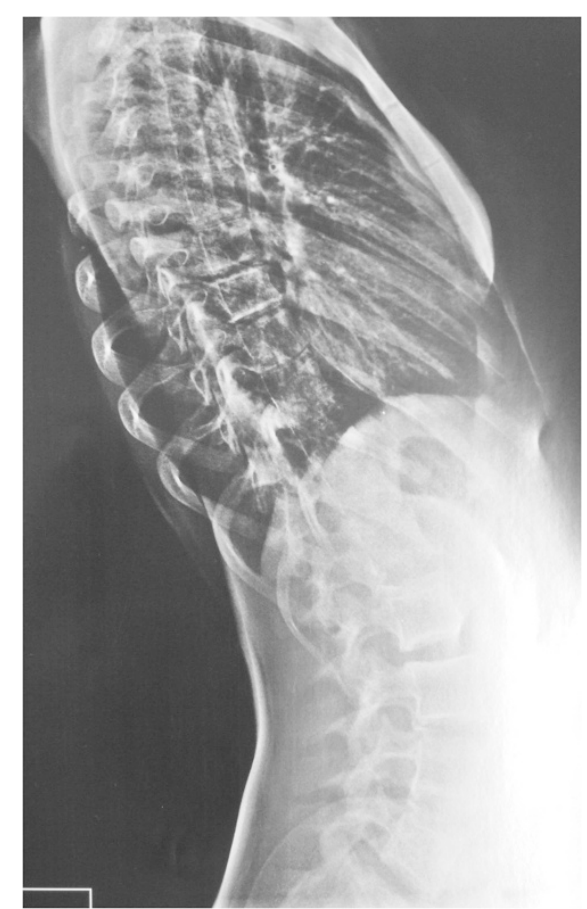

Fig. 4 Case 1: Radiological aspect of the scoliosis - Perfil view

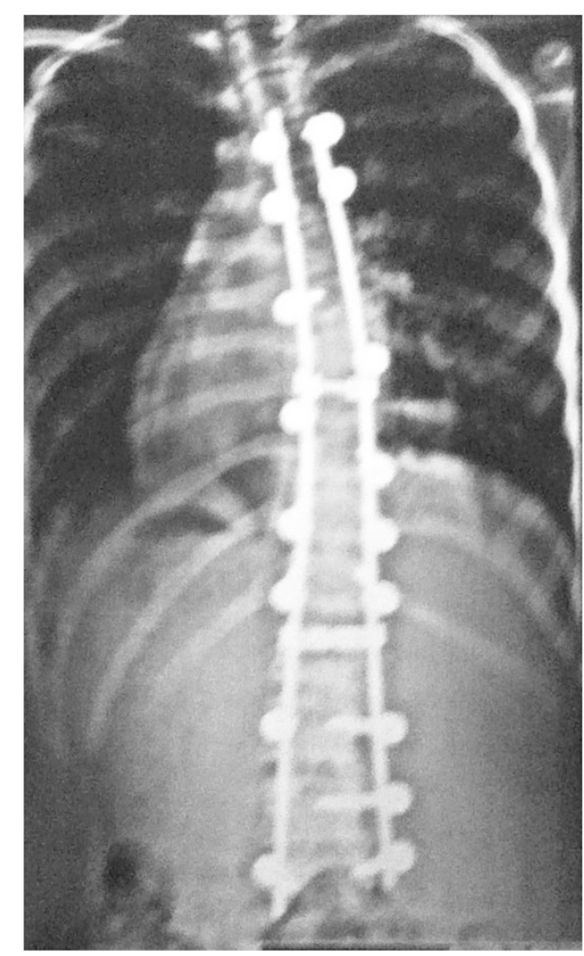

Fig. 5 Case 1: The patient after surgery - Radiograph in AP view
Fig. 6 Case 1: The patient after surgery - Clinical aspect
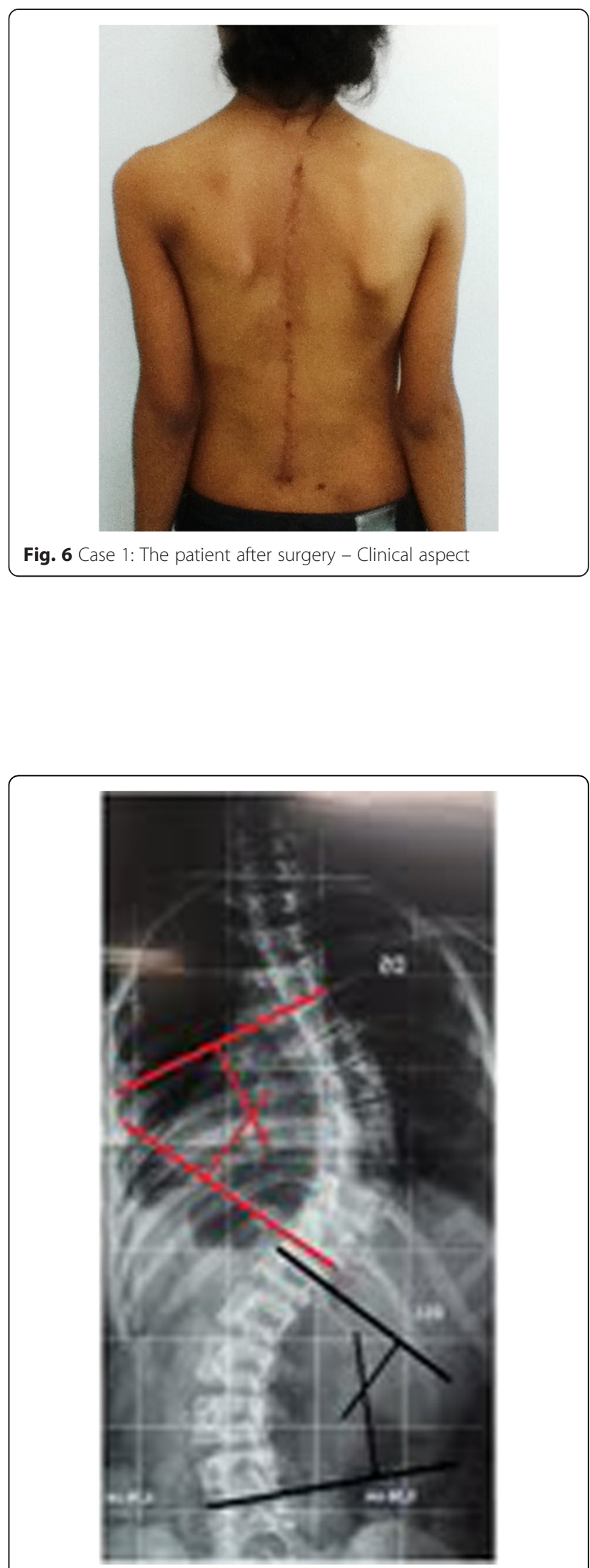

Fig. 7 Case 2: Radiological aspect of the scoliosis - AP view 
not suspected. After examination of biopsies and the central CORE histopathological finding, the next step will be to analyze the genetic code. However, this may require time due to the size of the mutations associated to the central CORE. It is important to explain that biopsies are routinely performed due to a research protocol of the institution in order to investigate the role of muscle balance in adolescent idiopathic scoliosis. The patients in this report had no relatives with deformities or altered motor development.

Previous studies have demonstrated a clear association between RYR1 gene mutations and susceptibility to malignant hyperthermia, which is a pharmacogenetic predisposition to potentially deadly adverse reactions that occur in response to volatile anesthetics and muscle relaxants [13-15]. This susceptibility is of particular interest to spine surgeons, as it can lead to progressive idiopathic scoliosis and require surgical treatment.

Because of the important association between scoliosis and paravertebral muscle imbalance, numerous studies have evaluated biopsies of the spinal rotator muscles for potential changes that may elucidate the etiology of AIS $[5,16-23]$. Here we describe two patients with clinical and radiological findings of AIS who were operated on and subjected to multifidus muscle biopsy, which

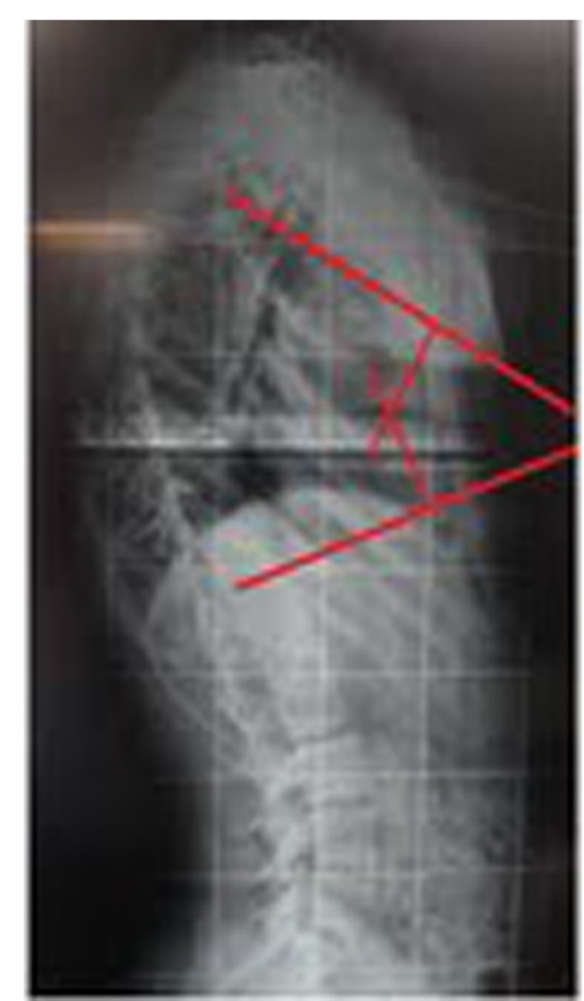

Fig. 8 Case 2: Radiological aspect of the scoliosis - Perfil
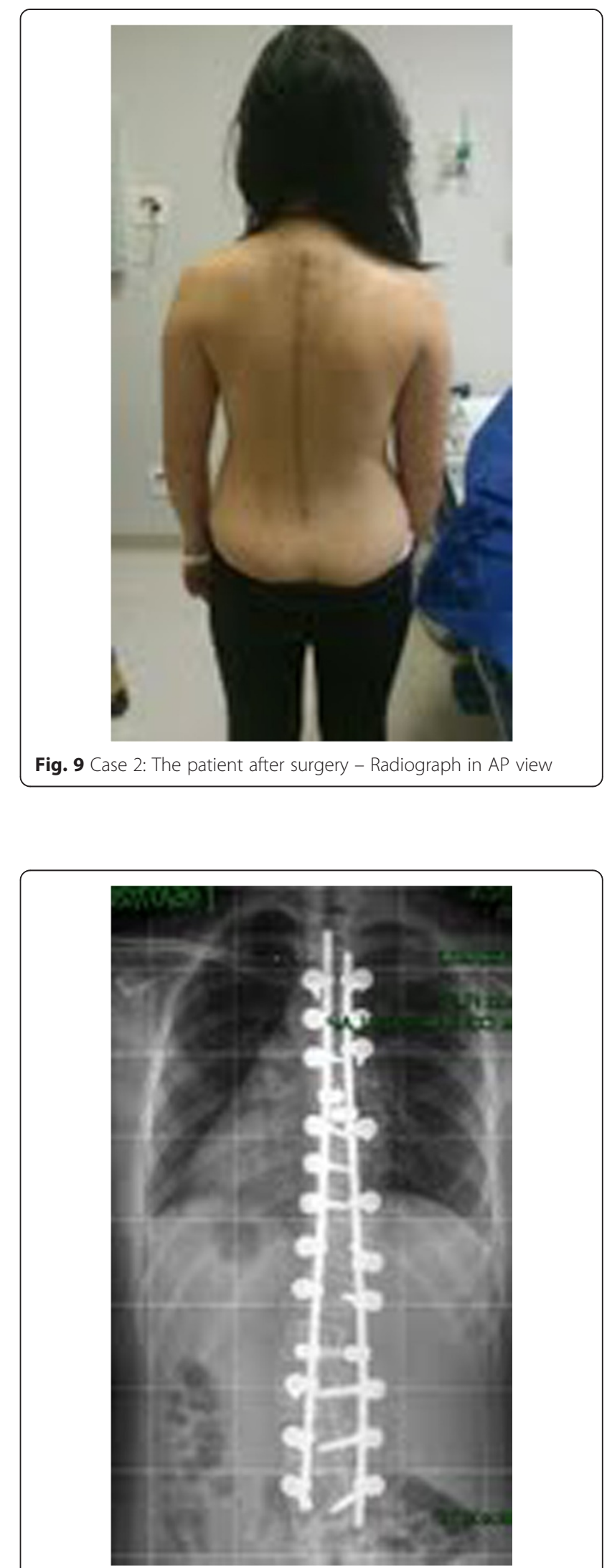

Fig. 10 Case 2: The patient after surgery - Clinical aspect 


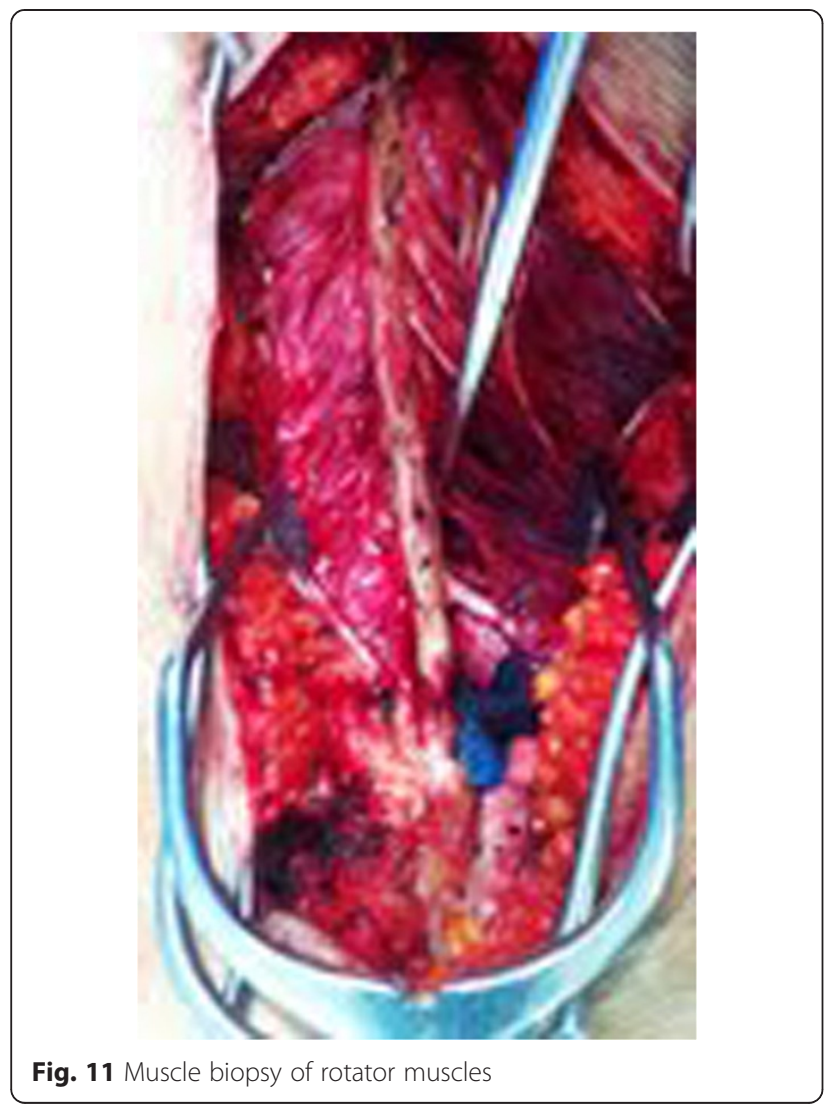

demonstrated anatomopathological results suggestive of core myopathy.

\section{Case presentation}

Case 1

This patient, who was referred to as TTF, was 12 years old, female and of a mixed background. Scoliosis was

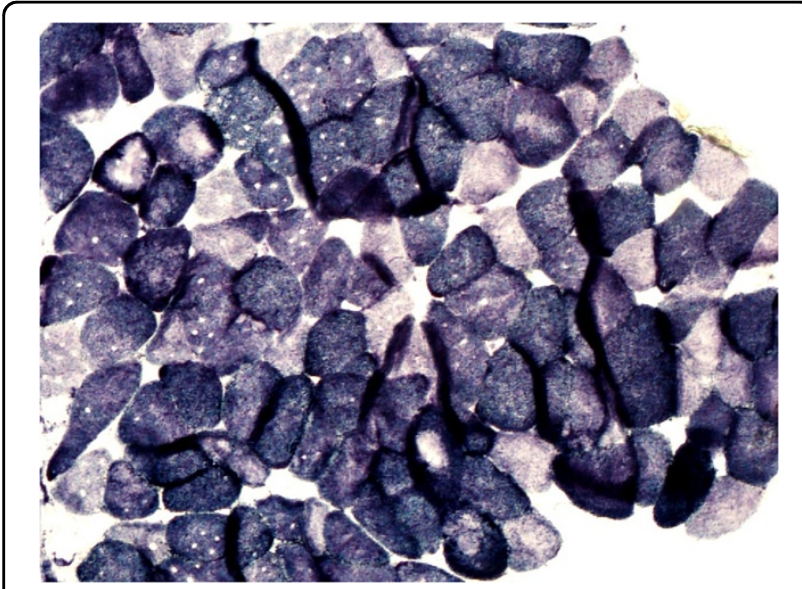

Fig. 12 Patient 1: Serial transverse sections of a biopsy from the multifidus muscle activity in many fibers. NADH $\times 100-$ Single prominent cores devoid of oxidative

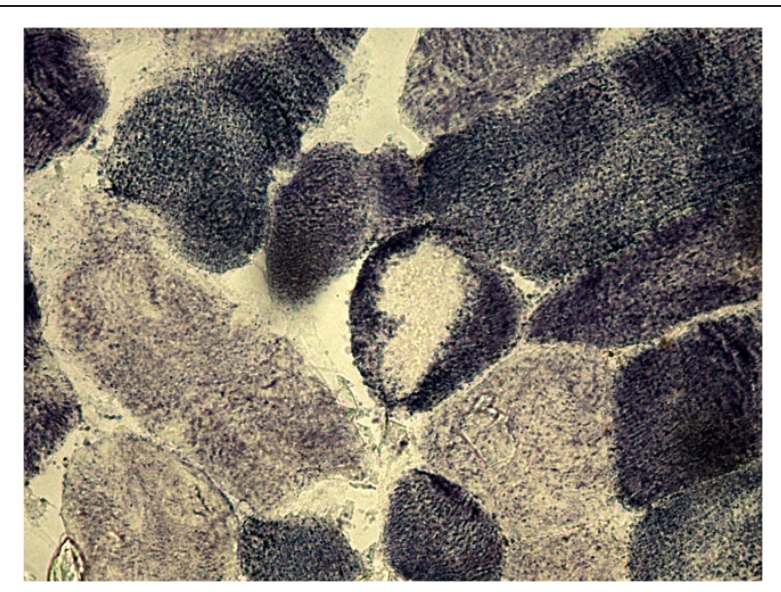

Fig. 13 Patient 1: Serial transverse sections of a biopsy from the multifidus muscle activity in many fibers. SDH $\times 400-$ The core is clearly delimited from the surrounding cytoplasm

first observed at age 10, but no other family members were affected. This patient had not yet reached menarche and demonstrated adequate neurological and motor development without any co-morbidities. The patient also demonstrated normal findings on a neurological examination. A physical examination did not detect skin changes, although the Adams maneuver revealed a thoracic right hump (Figs. 1 and 2). The scoliosis was classified as type III, according to the King and Lenke $1 \mathrm{C}$ classification, with a right thoracic curve of $53^{\circ}$ and a left lumbar curve of $52^{\circ}$ (Figs. 3 and 4).

The patient was monitored at the Outpatient Clinic of the Spine Group at Hospital Sao Paulo of the Federal University of São Paulo for two years and received surgery on October 31, 2011, Figs. 5 and 6.

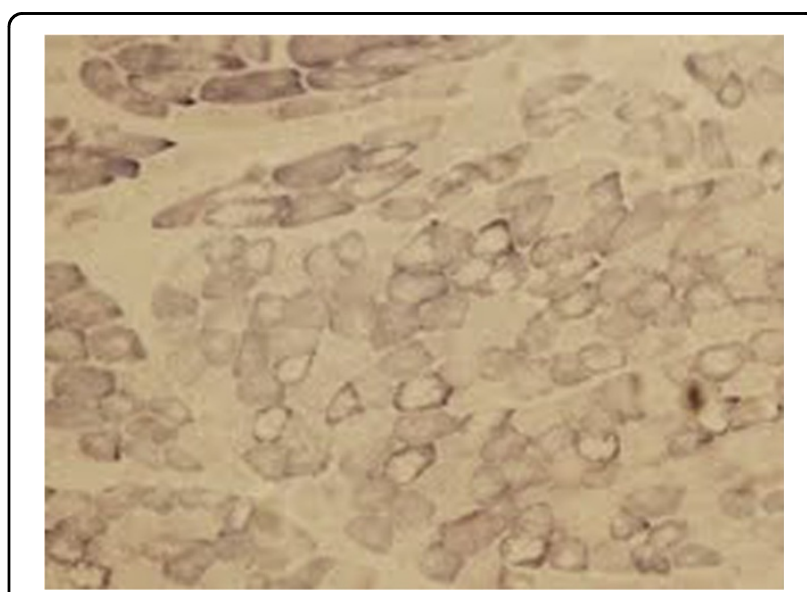

Fig. 14 Patient 2: Serial transverse sections of a biopsy from the multifidus muscle. SDH $\times 100$ - Single prominent cores devoid of oxidative activity 


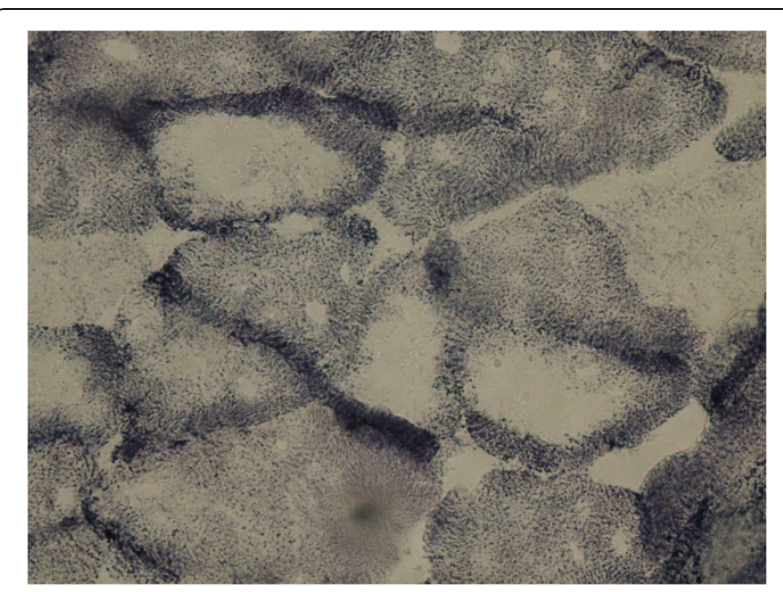

Fig. 15 Patient 2: Serial transverse sections of a biopsy from the multifidus. muscle. SDH $\times 400$ - The core is clearly delimited by the surrounding cytoplasm

\section{Case 2}

This patient, who was referred to as CYMH, was 12 years and 10 months of age, oriental and female. She reached menarche at 12 years and 2 months of age and demonstrated adequate neurological and motor development without any co-morbidities. Scoliosis was noted at 10 years of age. A physical examination showed no cutaneous alterations, the neurological examination was normal, and the Adams maneuver indicated a right thoracic hump. The scoliosis was classified as type II, according to the King classification system, and presented as a right thoracolumbar curve (T5-T11) of $62^{\circ}$, a left lumbar curve (T12-L4) of $55^{\circ}$ and kyphosis (T5-T12) of $50^{\circ}$ (Figs. 7 and 8 )). The patient was monitored at the Outpatient Clinic of the Spine Group at Hospital Sao Paulo of the Federal University of São Paulo for 2 years and received surgery on 02/07/2012, Figs. 9 and 10 .

Both patients families provided informed consent for intraoperative multifidus muscle biopsy at the apex of the thoracic curve on the concave and convex sides (Fig. 11). The parents/guardians of both patients gave consent for the publication of the case report and the pictures. Muscle biopsies from patients diagnosed with scoliosis are performed at the Hospital São Paulo after approval from the Ethics
Committee at the Federal University of São Paulo, for Histopathological Analysis in the Laboratory of Neuromuscle Diseases of the Department of Neurology and Neurosurgery of the Federal University of Sao Paulo.

\section{Histopathological evaluation}

The collection of muscle samples were performed according to the methods described by Schmidt et al. [24], whereby the extracted pieces were stored in a polystyrene box with ice and protected by a gauze pad. The material was immediately taken to the laboratory, where the fragments were removed and placed on a cork, fixed with tragacanth gum and covered with common talc. The set was then immersed in liquid nitrogen at $-180{ }^{\circ} \mathrm{C}$ for $20 \mathrm{~s}$, and the blocks were stored at $-80{ }^{\circ} \mathrm{C}$. Serial sections were cut using a cryostat at $-22{ }^{\circ} \mathrm{C}$ (Figs. 12, 13, 14 and 15).

Samples were analyzed for fiber type, muscular atrophy and hypertrophy, fatty proliferation, fibrosis, presence of hyaline fibers, mitochondrial proliferation, muscular necrosis, nuclear centralization, presence of central core myopathy and inflammation (Table 1).

The muscle fiber type I was prevalent in the biopsies. In both sides of the curve observed the presence of central core. The isolated description of these cases does not allow the comparison of the changes observed between the two sides of the curve. This analysis will be further after biopsies of a larger number of patients.

\section{Conclusions}

Regardless of clinical outcome, the reported changes in the patients may help to understand the real influence of the rotator muscles of the spine in the etiology and perpetuation of "idiopathic" scoliosis adolescents. It is necessary further studies with histopathological evaluation of paravertebral muscles in a larger number of patients to elucidate the role of muscle in the etiology and pathophysiology of AIS. However, if genetic analysis of these patients will be positive for genes related to myopathy CORE, these patients developed a secondary scoliosis and, therefore, they can't be classified as idiopathic scoliosis.

Table 1 Histopathological alterations in the paraspinal skeletal muscle of patients with adolescent idiopathic scoliosis

\begin{tabular}{|c|c|c|c|c|c|c|}
\hline CASE 1 & Necrosis & Atrophy & Hypertrophy & Fatty proliferation & Fibrosis & Inflammation \\
\hline Concave & Moderate & Moderate & Mild & Moderate & Moderate & Presence \\
\hline Convex & Mild & Mild & Scarce & Absent & Scarce & Absent \\
\hline \multicolumn{7}{|l|}{ CASE 2} \\
\hline Concave & Scarce & Scarce & Absent & Scarce & Scarce & Absent \\
\hline Convex & Scarce & Mild & Scarce & Moderate & Scarce & Absent \\
\hline
\end{tabular}




\section{Consent}

Written informed consent was obtained from both the patient and guardians for publication of this Case report and any accompanying images. A copy of the written consent is available for review by the Editor of this journal.

\section{Abbreviations}

AIS: Adolescent idiopathic scoliosis; Fig: Figure.

\section{Competing interests}

The authors declare that they have no competing interests.

\section{Authors' contributions}

RPL conceived of the study, and participated in its design and helped to write the manuscript. EBP, DEM, FF, DDC and LMRR participated in its design and helped to write the manuscript. BS and ASBO participated in the histopathological analysis and drafted the manuscript. MW conceived of the study, and participated in its design and coordination and helped to draft the manuscript. All authors read and approved the final manuscript.

\section{Acknowledgements}

FAPESP (Foundation of the Sao Paulo Research) due to the institutional support to the Federal University of Sao Paulo, in promoting the scientific development.

Received: 13 May 2014 Accepted: 13 July 2015

Published online: 05 August 2015

\section{References}

1. Nagai T, Tsuchiya Y, Maruyama A, Takemitsu M, Nonaka I. Scoliosis associated with central core disease. Brain Dev. 1994;16(2):150-2.

2. Mertz KD, Jost B, Glatzel M, Min K. Progressive scoliosis in central core disease. Eur Spine J. 2005;14(9):900-5. Epub 2005 May 31.

3. Ocaka L, Zhao C, Reed JA, Ebenezer ND, Brice G, Morley T, et al. Assignment of two loci for autosomal dominant adolescent idiopathic scoliosis to chromosomes 9q31.2-q34.2 and 17q25.3-qtel. J Med Genet; 2008;45:87-92.

4. Wajchenberg M, Lazar M, Cavaçana N, Martins DE, Licinio L, Puertas EB, et al. Genetic aspects of adolescent idiopathic scoliosis in a family with multiple affected members: a research article. Scoliosis. 2010;5:7.

5. Chagas JCM, Schimidt B, Puertas EB, Oliveira CEAS, Freitas AA. Histochemical study of lumbar rotator muscles in patients with adolescent idiopathic scoliosis. Rev Bras Ortop. 1998;33(2):111-8.

6. Jungbluth H, Sewry CA, Muntoni F. Core myopathies. Semin Pediatr Neurol. 2011;18(4):239-49. Review.

7. Jungbluth H. Multi-minicore Disease. Orphanet J Rare Dis. 2007:2:31. Review.

8. Jungbluth H. Central core disease. Orphanet J Rare Dis. 2007;2:25. Review.

9. Magee KR, Shy GM. A new congenital non-progressive myopathy. Brain. 1956;79(4):610-21.

10. Quinlivan RM, Muller CR, Davis M, Laing NG, Evans GA, Dwyer J, et al. Central core disease: clinical, pathological, and genetic features. Arch Dis Child. 2003;88(12):1051-5.

11. Sewry CA, Müller C, Davis M, Dwyer JS, Dove J, Evans G, et al. The spectrum of pathology in central core disease. Neuromuscul Disord. 2002;12(10):930-8.

12. Macintosh JE, Valencia F, Bogduk N, Munro RR. The morphology of the human lumbar multifidus. Clin Biomech. 1986;1(4):196-204.

13. Denborough MA, Dennett $X$, Anderson RM. Central-core disease and malignant hyperpyrexia. BMJ. 1973;1:272-3.

14. Denborough MA, Forster JF, Hudson MC, et al. Biochemical changes in malignant hyperpyrexia. Lancet. 1970;1:1137-8

15. Denborough MA, Forster JF, Lovell RR, et al. Anaesthetic deaths in a family. $\mathrm{Br} J$ Anaesth. 1962:34:395-6.

16. Fidler MW, Jowett RL, Troup JDG. Histochemical study of the function of multifidus in scoliosis. In: Zorab PA, editor. Scoliosis and Muscle. London: Heinemann; 1974. p. 184-92.

17. Maffuli N. Histochemical and physiological studies in idiopathic scoliosis. Ital J Orthop Traumatol. 1989;16(1):61-71.

18. Wong YC, Yau ACMC, Low WD, Chin NY, Lidowski FP. Ultrastructural changes in the back muscles of idiopathic scoliosis. Spine. 1977;2:251-60.
19. Kohsla S, Tredwell SJ, Day B, Shinn SL, Ovalle WK. An ultrastructural study of the multifidus muscle in progressive idiopathic scoliosis. J Neur Sci. 1980;46:12-21.

20. Ovalle WK, Tredwell SJ. The paraspinal myotendinous junction: a possible morphological marker for idiopathic scoliosis. Orth Trans. 1983;7:4.

21. Cotic V, Bizjak F, Turk V. The activity of proteinases of the paravertebral muscles in idiopathic scoliosis. In: ed. M. Pecina. Scoliosis and Kyphosis. Dubrovnik. 1983. p 250.

22. Blatt JM, Rubin E, Botin GC, Heller M. Impaired calcium pump activity in idiopathic scoliosis. Possible etiological role of a membrane defect. Orth Trans. 1984:8:143.

23. Fisher RE, Smith HF, Kusumi K, Tassone EE, Rawls A, Wilson-Rawls J. Mutations in the Notch pathway alter the patterning of multifidus. Anat Rec (Hoboken). 2012;295(1):32-9.

24. Schmidt B, Gabbai AA, Oliveira ASB, Braga MB, Castelo Filho A, Laredo FJ Biópsia muscular, nova metodologia: a dança dos "farabeufs". Rev Bras Ortop. 1988;23:21-6.

\section{Submit your next manuscript to BioMed Central and take full advantage of:}

- Convenient online submission

- Thorough peer review

- No space constraints or color figure charges

- Immediate publication on acceptance

- Inclusion in PubMed, CAS, Scopus and Google Scholar

- Research which is freely available for redistribution 